\title{
Development of a new gene expression vector for Thermus thermophilus using a silica-inducible promoter
}

\author{
Yasuhiro Fujino ${ }^{1}$, Shuichiro Goda ${ }^{2}$, Yuri Suematsu ${ }^{1}$ and Katsumi Doi ${ }^{{ }^{*}}$ (D)
}

\begin{abstract}
Background: Thermostable enzymes are commonly produced in mesophilic hosts for research and bioengineering purposes. However, these hosts do not overexpress the active forms of some biologically functional thermoenzymes. Therefore, an efficient thermophilic expression system is needed. Thermus thermophilus contains an easily manipulable genome and is therefore among the best candidate microbes for a "hot" expression system. We previously identified a strong and inducible promoter that was active in T. thermophilus under supersaturated silica conditions. Here, we report a new heterologous gene expression system based on a silica-inducible promoter in T. thermophilus.

Results: A Thermus sp. A4 gene encoding thermostable $\beta$-galactosidase was cloned as a reporter gene into the expression vector $\mathrm{pSix} 1$, which contains a selection marker that confers thermostable resistance to hygromycin and a 600 bp DNA region containing a putative silica-inducible promoter. $\beta$-galactosidase activity was 11 -fold higher in the presence than in the absence of $10 \mathrm{mM}$ silicic acid. SDS-PAGE revealed a prominent band corresponding to $73 \mathrm{kDa}$ of $\beta$-galactosidase, and this enzyme was expressed as an active and soluble protein (yield: $27 \mathrm{mg} / \mathrm{L}$ ) in Thermus but as an inclusion body in Escherichia coli. Truncation of the putative silica-inducible promoter region in Thermus expression vector improved the yield of the target protein, possibly by avoiding plasmid instability due to homologous recombination. Finally, we developed an expression vector containing the pSix 1 backbone and a 100 bp DNA region corresponding to the silica-inducible promoter. We used this vector to successfully express the active form of glutamate dehydrogenase from Pyrobaculum islandicum (PisGDH) without additional treatment (yield: $9.5 \mathrm{mg} / \mathrm{L}$ ), whereas the expression of active PisGDH in E. coli required heat treatment.
\end{abstract}

Conclusion: We successfully expressed the thermostable $\beta$-galactosidase and PisGDH in T. thermophilus as active and soluble forms and achieved with our system the highest known protein expression levels in this species. These thermoenzymes were expressed in active and soluble forms. Our results validate the use of our silica-inducible expression system as a novel strategy for the intracellular overexpression of thermostable proteins.

Keywords: Silica, Gene expression, Inducible, Thermus thermophilus

*Correspondence: doi@agr.kyushu-u.ac.jp

${ }^{1}$ Institute of Genetic Resources, Faculty of Agriculture, Kyushu University, 744 Motooka, Nishi-ku, Fukuoka 819-0395, Japan

Full list of author information is available at the end of the article

\section{Background}

Enzymes from thermophiles are highly stable and have attracted significant interest in both basic research and bioengineering applications [1-3]. Currently, thermostable enzymes used in these context are produced commonly in mesophilic hosts [4], especially Escherichia coli. These surrogate hosts can successfully express soluble forms of the target proteins. Although

(C) The Author(s) 2020. This article is licensed under a Creative Commons Attribution 4.0 International License, which permits use, sharing, adaptation, distribution and reproduction in any medium or format, as long as you give appropriate credit to the original author(s) and the source, provide a link to the Creative Commons licence, and indicate if changes were made. The images or other third party material in this article are included in the article's Creative Commons licence, unless indicated otherwise in a credit line to the material. If material is not included in the article's Creative Commons licence and your intended use is not permitted by statutory regulation or exceeds the permitted use, you will need to obtain permission directly from the copyright holder. To view a copy of this licence, visit http://creativeco mmons.org/licenses/by/4.0/. The Creative Commons Public Domain Dedication waiver (http://creativecommons.org/publicdomain/ zero/1.0/) applies to the data made available in this article, unless otherwise stated in a credit line to the data. 
the ability to remove mesophilic host proteins by simple heat denaturation during the production process is advantageous, currently only a few biologically functional thermoenzymes are overexpressed in their active forms in mesophilic hosts. Moreover, these target proteins often aggregate to form "inclusion bodies" that are susceptible to misfolding when expressed at relatively lower temperatures than those experienced in their native hosts [5]. Consequently, the use of thermophilic hosts for enzyme production requires the development of genetic tools that can overcome these limitations.

Thermus is among the most ubiquitous genera of thermophilic bacteria. Thermus species are characterized by high growth rates and cell yields in culture and a high level of natural competency, and thus exhibit strong potential for production in laboratory settings [1]. Although several studies have demonstrated the potential use of these organisms as cell factories [5-9], only moderate levels of protein overexpression were achieved except in studies that used the expression vector pMKE1, which utilizes the respiratory nitrate reductase operon promoter (Pnar). Moreover, despite the achievement of up to 200-fold overexpression levels with this Pnar-based expression system in facultative anaerobic derivatives of $T$. thermophilus HB27 (HB27::nar), the resulting proteins were almost undetectable by Coomassie brilliant blue staining. To date, successful expression at practical levels has only been achieved using pMKE2, a variation of pMKE1 that was created by modifying the sequences between Pnar and the start codon [7]. Recently, Aulitto and co-workers achieved a high level of homologous $\alpha$-galactosidase production $(5 \mathrm{mg} / \mathrm{L})$ in $T$. thermophilus $\mathrm{HB} 27$ under the control of pMKE2 [10]. However, no report has described a sufficient level of heterologous expression in Thermus cells.

Despite the noted challenges, overexpression in T. thermophilus remains a potentially useful tool for the overexpression of thermostable enzymes or the selection of thermostable mutants from mesophilic proteins via directed evolution. We considered that these challenges might be resolved by a strong promoter that would enable more effective expression. We previously reported the expression of a specific silica-induced protein (Sip) in $T$. thermophilus exposed to supersaturated silica [11]. We further identified this Sip as a $\mathrm{Fe}^{3+}$-binding ABC transporter encoded by a gene for which the transcription was regulated strictly by a ferric uptake regulator (Fur) via a previously reported mechanism [12]. Importantly, the sip promoter might be sufficiently strong to mediate heterologous expression, as indicated by the greater than tenfold increase in Sip expression under induced conditions relative to un-induced conditions and the prominent protein band of $35 \mathrm{kDa}$ detected by Coomassie brilliant blue staining.

The production of active forms of thermoenzymes is important for both enzymological studies and industrial applications. A good example is glutamate dehydrogenase from Pyrobaculum islandicum (PisGDH). When expressed heterologously in E. coli, PisGDH was not fully active despite its status as a soluble protein. However, when the recombinant enzyme was heated at $90{ }^{\circ} \mathrm{C}$ or exposed to $5 \mathrm{M}$ urea, its activity increased to a level comparable to that of the native enzyme [13]. PisGDH forms a hexameric structure, and heat-induced subunit rearrangement is considered essential for its activation. Therefore, we would expect to observe the expression of fully active PisGDH in Thermus cells, which are cultured at a high temperature $\left(70{ }^{\circ} \mathrm{C}\right)$. In this report, we describe the development of a new heterologous expression system for T. thermophilus HB27 in which supersaturated silica is used as the inducer. Furthermore, we demonstrate the expression of a sufficient amount of an active and soluble heterologous gene product. Our findings indicate the potential application of this system for the expression of thermostable enzymes at practical quantities.

\section{Results and discussion}

Construction of a silica-inducible expression vector and reporter plasmids

We previously reported that Thermus strains produced a specific Sip in the presence of supersaturated silica [12]. This Sip exhibited high homology with a $\mathrm{Fe}^{3+}$-binding $\mathrm{ABC}$ transporter that plays a role in $\mathrm{Fe}^{3+}$ uptake. The expression of Sip is thought to be a response to iron starvation stress, which can be induced by the addition of supersaturated negatively charged colloidal silica that captures $\mathrm{Fe}^{3+}$ ions. The ferric uptake regulator (Fur), a repressor of iron uptake-related gene expression, responds to low environmental iron levels and is released form promoter region to enhance downstream gene transcription. In an earlier study, the cultivation of Thermus cells in medium containing $10 \mathrm{mM}$ silica led to an approximately tenfold higher Sip expression level relative to that observed in the absence of silica [11]. Therefore, we speculated that the sip promoter, which controls protein expression via a mechanism induced by silicic acid, could be utilized to express heterologous proteins in Thermus.

The construction of the plasmid DNA construct used in this study is illustrated in Fig. 1. We inserted a multicloning site (MCS) and a $600 \mathrm{bp}$ fragment of a putative silica-inducible promoter region from $T$. thermophilus HB8 into the pYK596 plasmid, which contains a thermostable hygromycin resistance gene. Next, the Xho I 

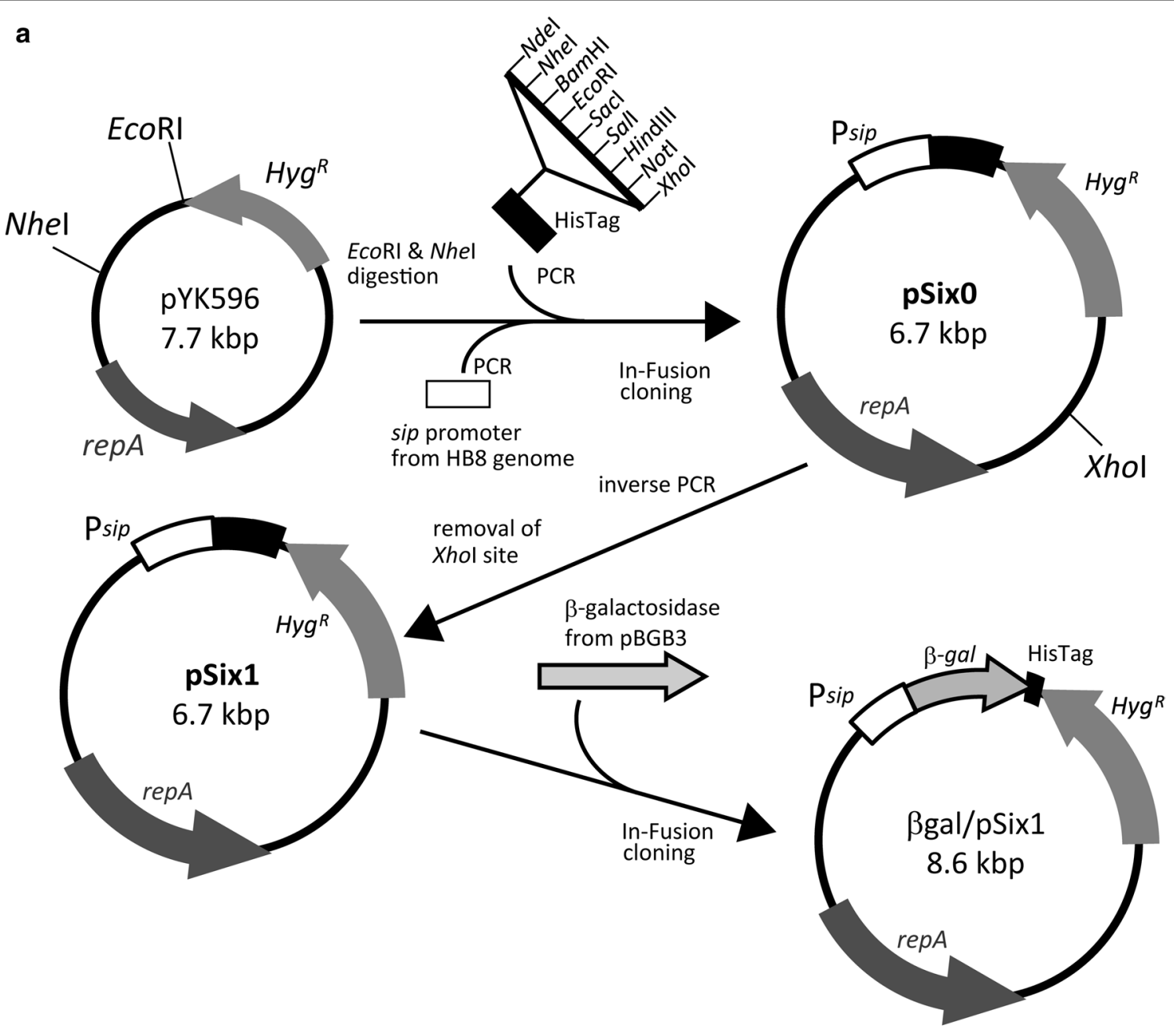

b

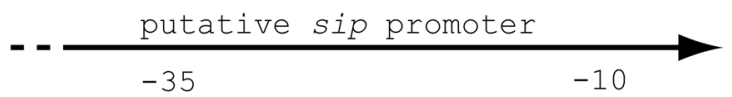

GAATACTTGACATTCCCCCCGCCCCGGGGTACCCTCCTTCCCGGGAGGCGCGCCTCCCGAGGAGAACGGAGG

$\frac{\text { NdeI }}{\text { TACATATGGCTAGCATGACTGGTGGACAGCAAATGGGTCGCGGATCCGAATTC }} \frac{\text { NhAGCTCCGTCGACAAGCTT }}{\frac{\text { BamHI }}{\text { GAATARI }}}$

$\frac{\text { NotI }}{\text { GCGGCCGCACTCGAG }} \frac{\text { XhoI }}{\text { CACCACCACCACCACCACTGAGATCCGGCTGCTAACAAAGCCCGAAAGGAAGCTGAG }}$

TTGGCTGCTGGCCACCGCTGAGCAATAACTAGCATAACCCCTTGGGGCCTCTAAACGGGTCTTGAGGGGTTT
$\overline{\text { TTTGCTGAAAGGAAATTCTTATCACCCGGCTCCGGATCGGACGATTGCGTCGCATCGACTCTGCGCCCAAGC }}$
Hyg $^{\mathrm{R}}$

Fig. 1 a Construction of the expression vector pSix 1 for Thermus strains. The plasmid pYK596, which possesses a hygromycin resistance gene, was digested using ECORI and Nhe I. Two PCR-amplified fragments, a multi-cloning site derived from PET21a, and a putative silica-inducible protein (sip) promoter region [12] were cloned into pYK596 using an In-Fusion cloning kit. The Xho I site on the PYK596 backbone was deleted by inverse PCR, and the resultant plasmid was named pSix1. To complete the Miller assay, a thermostable $\beta$-galactosidase gene from the Thermus sp. A4 was cloned downstream of the sip promoter of pSix 1 to yield $\beta$ gal/pSix 1. b Sequence of pSix1. The -35 and -10 regions of the sip promoter are underlined. The experimentally determined transcription initiation site $(+1)$ is indicated in bold, and the putative ribosome binding site (rbs) is underlined. Restriction sites in the multi-cloning site and $6 \times$ histidine tag sequences are indicated above the sequence 
site on the pYK596 backbone was eliminated by sitedirected mutagenesis to yield the plasmid pSix1. To enable a reporter assay, a gene encoding a thermostable $\beta$-galactosidase derived from Thermus sp. A4 ( $\beta$ gal) was inserted into pSix1 at the Nde I and Xho I sites within the MCS. All the modified regions in this new $\beta$ gal/pSix1 reporter plasmid were confirmed using an ABI 3130 genetic analyzer (Applied Biosciences, Foster City, CA, USA).

\section{Effect of supersaturated silica on the growth of $T$. thermophilus}

As described above, the addition of silicic acid to Thermus cells may induce stress. Therefore, the effects of silicic acid on the growth of Thermus cells was monitored. Growth inhibition was observed in T. thermophilus HB27 cells harboring $\beta \mathrm{gal} / \mathrm{pSix} 1$ after cultivation in medium containing various concentrations of silica, particularly those corresponding to supersaturation $(>5 \mathrm{mM}$ at $70{ }^{\circ} \mathrm{C}$; Additional file 1: Figure S1). Only slight cell growth inhibition was observed at $6.7 \mathrm{mM}$ silica, whereas significant inhibition was observed at $10 \mathrm{mM}$ silica, as indicated by an optical density at $660 \mathrm{~nm}\left(\mathrm{OD}_{660}\right)$ value that was reduced to nearly half the value observed at $0 \mathrm{mM}$ silica. Although growth appeared to be impeded by silica-induced iron deficiency, the lack of a severe effect of exposure to $10 \mathrm{mM}$ silica on the growth of wildtype T. thermophilus HB27 (data not shown) suggests that the observed growth inhibition may be attributable to the allocation of various energy resources toward protein expression rather than cell growth.

\section{Effect of the silicic acid concentration on $\beta$-galactosidase activity}

$\beta$-Galactosidase is a convenient enzyme, as its activity can be quantitated precisely in liquid assays [14]. Consequently, it has been used widely as a reporter to monitor gene expression. Approximately 30 years ago, Koyama and co-workers first reported the use of a thermostable $\beta$-galactosidase gene as a reporter in Thermus strains [6]. Since then, several researchers have attempted to use $\beta$-galactosidase assays in studies of Thermus $[8,15]$. However, wild-type Thermus cells exhibit a high level of background activity, and consequently it has been difficult to assess the precise level of promoter activity, particularly if the target promoter is relatively weak. To overcome this limitation, Fujita and co-workers recently developed a precise reporter assay system in which the background activity was reduced by disrupting all $\beta$-galactosidase genes and the phytoene synthase gene $(\operatorname{crtB})$ in the host cells [16].

Despite those earlier findings, we selected wild-type HB27 as the host strain in our $\beta$-galactosidase assay because a previously reported qRT-PCR analysis revealed strong sip promoter activity (16-fold increase in response to $10 \mathrm{mM}$ silica) [12]. As expected, exposure to $10 \mathrm{mM}$ silica induced a sufficiently high level of $\beta$-galactosidase activity to enable a comparison between the induced and non-induced conditions. The $\beta$-galactosidase activity levels measured after a $24 \mathrm{~h}$ cultivation at various silica concentrations are indicated in Fig. 2. Notably, the $\beta$-galactosidase activity level was negligibly lower in non-induced condition than in cells under inducing conditions. HB27 cells with empty pSix1 vector exhibited an activity level $<10$ Miller unit (MU), similar to that measured in HB27 cells without plasmid (data not shown). Relative to cells harboring pSix1, cells harboring the $\beta \mathrm{gal} / \mathrm{pSix} 1$ plasmid exhibited slightly higher levels of activity (17-26 MU) when exposed to silica concentrations of $0-6.7 \mathrm{mM}$ silica, suggesting leaky expression. However, when cultured in $10 \mathrm{mM}$ silica, cells harboring $\beta$ gal/pSix 1 achieved $\beta$-galactosidase activity levels as high as $190 \mathrm{MU}$ (11-fold higher than that observed at $0 \mathrm{mM}$ silica), indicating strong sip promoter activity. On the other hand, $\beta$-galactosidase activity levels reached the plateau in higher silica concentration $(>10 \mathrm{mM})$. Moreover, higher concentrated silica solution was difficult to handle because dissolved silica easily precipitated during the cultivation. Accordingly, we set optimum silica concentration for induction to $10 \mathrm{mM}$.

Exposure to supersaturated silica indirectly causes iron starvation, leading to induction of the sip promoter. Therefore, we also tested direct iron starvation caused by iron chelators such as 2,2'-dipyridyl (DP) and 1,10phenanthroline (phen). However, the addition of DP

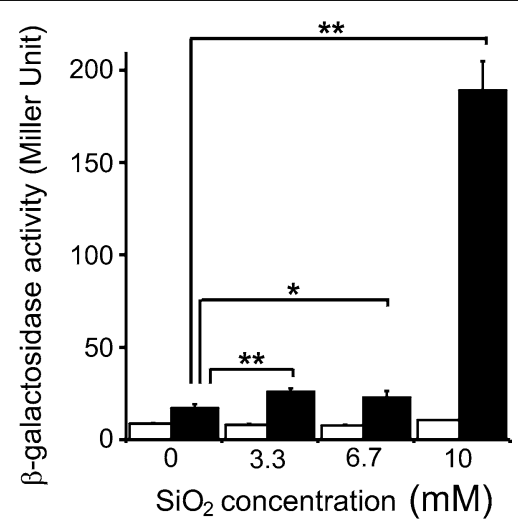

Fig. 2 Induction of the sip promoter with different concentrations of silicic acid. A $5 \%$ suspension of pre-culture was inoculated in freshly prepared TM medium containing silicic acid and cultivated for $24 \mathrm{~h}$. The $\beta$-galactosidase activity levels in culture are given in Miller units (MU). White bar: HB27 with pSix1 (empty vector), black bar: HB27 with $\beta \mathrm{gal} / \mathrm{pSix} 1$. Values are expressed as means \pm standard deviations $(n=3)$ 
and phen (0.5-5 $\mathrm{mM})$ did not have a notable effect on $\beta$-galactosidase expression (data not shown). This result implies that Thermus can utilize chemically masked iron species, such as siderophores [17]. Therefore, the addition of supersaturated silica is a superior method for initiating sip promoter-mediated transcription.

\section{Effect of medium exchange on gene expression}

As described above, $\beta$-galactosidase activities were measured after a continuous exposure to silica from the beginning of the cultivation. However, induction during the middle or late exponential growth phase is generally much more advantageous for protein expression. Unlike isopropyl- $\beta$-D-1-thiogalactopyraoside (IPTG), highly concentrated silica is easily precipitated. Consequently, it is difficult to achieve an appropriate silicic acid concentration when using a stock solution. We opted for a medium exchange to achieve silica-mediated induction during the late exponential growth phase. Briefly, cells harboring $\beta \mathrm{gal} / \mathrm{pSix} 1$ were cultivated in normal TM medium without silica until the $\mathrm{OD}_{660}$ value reached 0.6. The cells were then collected by centrifugation and inoculated in fresh medium containing $10 \mathrm{mM}$ silica. The $\beta$-galactosidase activity in the cultures increased gradually along with the duration of silica exposure, reaching a plateau at $12 \mathrm{~h}$. As shown in Additional file 1: Table S3, however, the activity levels after medium exchange were lower than those observed after uninterrupted cultivation in medium containing supersaturated silica. Although the maximum activity value achieved in a medium exchange culture was 3.6-fold higher than that observed before induction, this maximum activity was less than one-third of the value observed after an uninterrupted culture period in $10 \mathrm{mM}$ silica. In a recent report, we similarly observed that medium exchange was ineffective in an E. coli-based protein expression system that utilizes silica as an inducer in advance [12]. As discussed in previous reports, this decrease in protein expression may be attributable to intracellular iron storage proteins. Because normal silica-free medium contains sufficient iron, cells grown in this medium can take up sufficient levels of iron to maintain growth and can store this element as bacterioferritin [18]. As these bacterioferritin molecules are then passed to daughter cells, several generations may be required to provoke iron starvation. Therefore, exposure to silica throughout the cultivation period resulted in much higher protein expression levels.

\section{Immunodetection of His-tagged $\beta$-galactosidase}

We next examined whether our T. thermophilus-based heterologous expression system could be applied for practical use. In light of our previous analysis, $\beta$-galactosidase was induced by continuous exposure to $10 \mathrm{mM}$ silica.
After a 48-h cultivation, the cell extracts were subjected to SDS-PAGE and Western blotting (Fig. 3). In the absence of silicic acid, no protein bands corresponding to $\beta$-galactosidase were observed in either the insoluble or soluble fraction after an SDS-PAGE analysis, and no corresponding bands were detected by Western blotting. By contrast, the extracts of cells exposed to $10 \mathrm{mM}$ silica produced clearly visible bands on SDS-PAGE. Bands corresponding to His-tagged $\beta$-galactosidases were also detected on Western blots. Particularly strong bands were detected in the soluble fraction, suggesting that the recombinant form of $\beta$-galactosidase expressed in $T$. thermophilus was correctly folded.

If heterologous proteins do not require post-translational modifications, E. coli is usually first selected to obtain enough material for both research and industrial applications. However, overexpressed proteins fail to reach a correct conformation and form insoluble aggregates of nonnative proteins called inclusion bodies [19]. Formation of inclusion bodies in $E$. coli is mainly due to rapid protein production during the forced expression, however, with respect to thermoenzymes, domain misfolding is also attributable to lower temperature than their natural hosts [5]. When we expressed recombinant $\beta$-galactosidase in E. coli, we found that most of the protein was expressed in the insoluble fraction, indicating the formation of inclusion bodies (right panel in Fig. 3). This discrepancy in protein production between the species may be attributable to the high temperature under which T. thermophilus is cultivated, as thermophilic enzymes occasionally require exposure to high temperatures to achieve correct folding into catalytically active forms [13, 20-22]. Our successful achievement of soluble protein expression in T. thermophilus suggests that our expression vector can serve as a useful genetic tool for the expression of thermostable gene products that would be insoluble when produced in E. coli.

Previously, Moreno and co-workers reported the achievement of heterologous gene expression in T. thermophilus at a practical level [7]. The system developed by these authors adopted the nitrate reductase operon (nar operon) in T. thermophilus HB8, which is strongly transcribed in response to nitrate under anoxic conditions [23]. Therefore, their system requires the specific host strain T. thermophilus HB27::nar (transplanted with the nar cluster from HB8) to enable anaerobic growth in the presence of nitrate [24]. By contrast, our system, which is driven by a silica-inducible promoter, does not require a genetically modified host strain because Sip induction is common among Thermus species and is basically controlled by ferric uptake regulators that are inherent in most microorganisms. These features may enhance the convenience of our system and its applicability to 


\section{T. thermophilus}

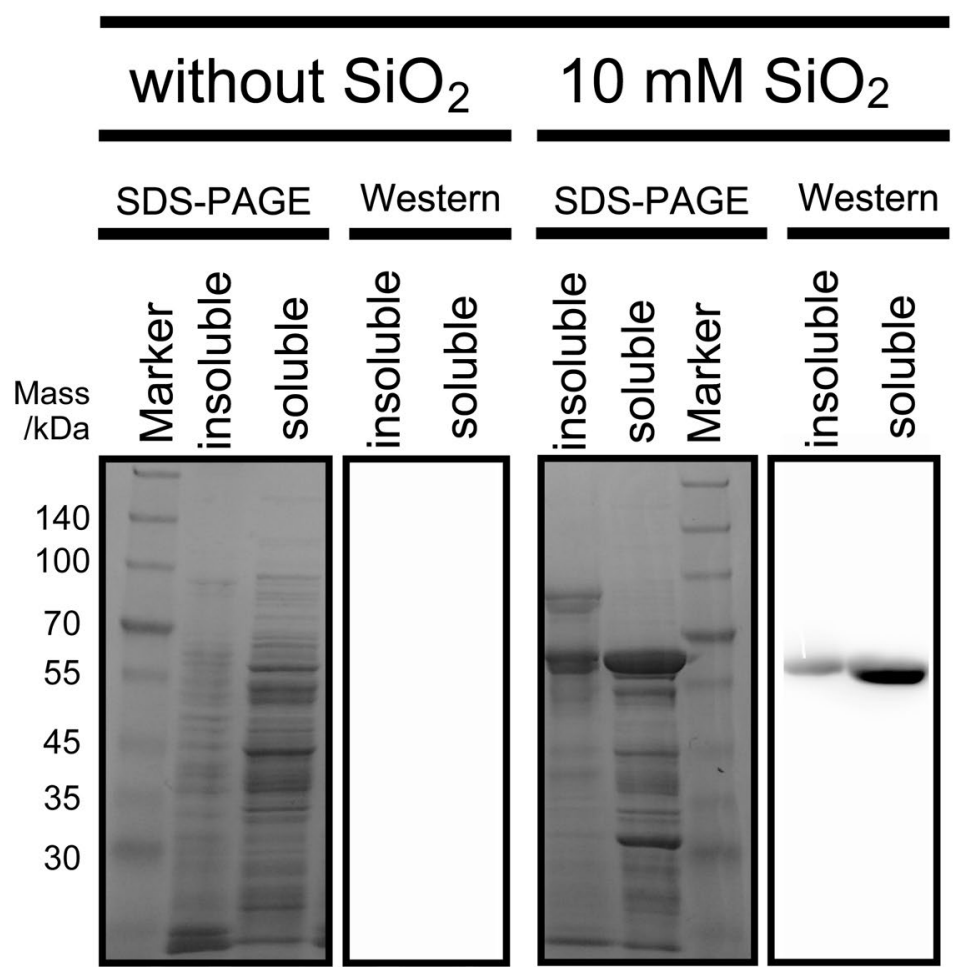

E. coli

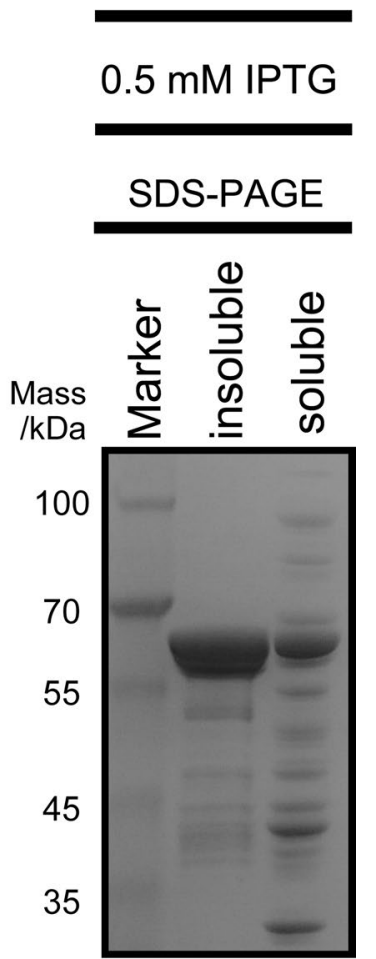

Fig. 3 SDS-PAGE and Western blot analysis of recombinant proteins produced in T. thermophilus and E. coli. Left: Expression of His-tagged $\beta$-galactosidase in T. thermophilus HB27 in response to 0 and $10 \mathrm{mM}$ silicic acid. Right: Expression of recombinant $\beta$-galactosidase in E. coli. Cells were harvested by centrifugation and disrupted by sonication. The soluble fraction was separated from insoluble fractions by centrifugation. Each lane contains $10 \mu \mathrm{g}$ of total protein. His-tagged proteins were detected using anti-His-tag mAb-HRP-DirecT

hundreds of other strains in the genus Thermus. These advantages of a silica-inducible promoter highlight the potential use of T. thermophilus as a host strain for the expression of thermostable proteins and other practical applications (e.g., microbial bioprocesses) that require relatively high temperatures.

\section{Promoter deletion analysis}

Next, deletion mutants of $\beta \mathrm{gal} / \mathrm{pSix} 1$ were constructed to determine the minimum region of the active promoter. We found that a $100 \mathrm{bp}$ region upstream of the sip coding sequence (CDS) exhibited significant promoter activity, whereas a 50 bp upstream region exhibited no activity. Also the upstream region 600 to $100 \mathrm{bp}$ distal from the sip CDS did not appear to be important for promoter activity. We previously determined transcriptional start site (TSS) of the sip gene under supersaturated silica condition in T. thermophilus strain HB8 [12]. Although we used T. thermophilus strain HB27 as an expression host, putative sip promoter from strain HB8 was introduced into $\beta \mathrm{gal} / \mathrm{pSix} 1$. DNA sequence of this promoter fragment from HB8 is almost identical with that of HB27
(Additional file 1: Figure S2), thus, it seems to function in HB27 cells in the same manner. Therefore, the essential sip promoter region appeared to be contained within the region 100 to $50 \mathrm{bp}$ upstream of the start of the sip CDS (Fig. 4a). In our earlier reports, it was experimentally confirmed that a Fur (TTHA0344 product) interacted with the region within $150 \mathrm{bp}$ upstream of sip CDS, however, Fur binding consensus sequence seen in other bacteria was not found in T. thermophilus [12]. Although the sequence of Fur binding site in T. thermophilus remains unclear, 100 bp upstream region of the sip CDS can contain at least one promoter region and one Fur binding site.

Interestingly, the 100-bp promoter yielded a $\beta$-galactosidase activity level of approximately $1200 \mathrm{MU}$, which was 6 times higher than the level achieved with the 600-bp promoter region. This phenomenon was also confirmed by SDS-PAGE, which revealed that the shorter promoter region yielded a stronger thermostable $\beta$-galactosidase band (Fig. 4b). Our results suggest that the 100-bp sip promoter region yielded much more efficient expression of the recombinant protein than the 

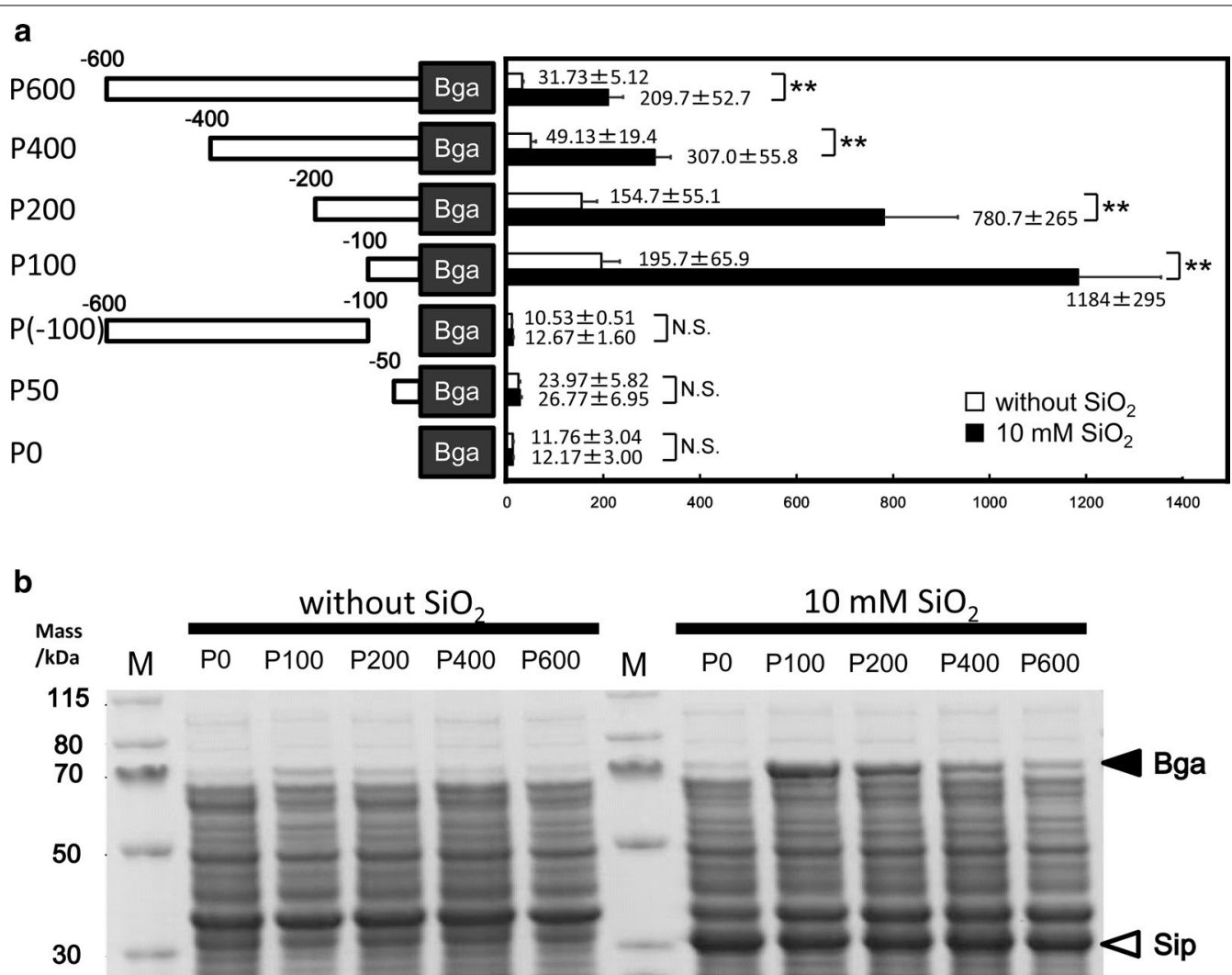

Fig. 4 Promoter deletion analysis using a $\beta$-galactosidase reporter system. a Schematic figure of the promoter region and $\beta$-galactosidase activity in the presence or absence of supersaturated silica. The $\beta$-galactosidase activity levels are presented as the mean \pm standard deviations of three independent experiments and are shown in Miller units. The white and black bars indicate the activity levels in response to 0 and $10 \mathrm{mM}$ silica, respectively. $\mathbf{b}$ Image of an SDS-PAGE analysis of expressed proteins from plasmids containing promoter deletion mutants. Cells were harvested from $24 \mathrm{~h}$ cultures and disrupted by sonication, after which the soluble fractions were subjected to 12\% SDS-PAGE. The black and white arrowheads indicate the bands corresponding to $\beta$-galactosidase and silica-induced protein, respectively

original expression vector pSix1. Consequently, we truncated the promoter region of pSix1 to 100 bp to yield pSix3.

Mini-prep extraction revealed that pSix1 produced a lower DNA yield than the original plasmid, pYK596, suggesting an issue of stability with the former construct. Because the sip promoter regions in the plasmid DNA (derived from T. thermophiles HB8) and in the host chromosomal DNA (T. thermophiles HB27) are so similar (99\%), we suspected that homologous recombination might have occurred. Specifically, a single-crossover homologous recombination event would have led to the insertion of plasmid DNA into the chromosomal DNA. Additional file 1: Figure S3_A presents a schematic of the gene arrangements of normal chromosomal DNA, pSix1, and chromosomal DNA in a single-crossover mutant. To confirm the singlecrossover homologous recombination event, total DNA from various transformants harboring the plasmids with different promoter regions were extracted and then subjected to PCR amplification analysis. As shown in Additional file 1: Figure S3_B, $\beta$ gal/pSix1 yielded a band that corresponded to the single-crossover region between chromosomal and plasmid DNA. No crossover associated bands were observed with any other plasmids, including pSix3, indicating the stable maintenance of these plasmids in the host cells.

In our experiments, the 100-bp promoter yielded the highest expression level. However, this promoter was also associated with a higher leaky expression level than the long promoter. We speculated that this might be attributable to a competition effect of Fur protein, because there are more Fur binding sites on plasmid DNA competing for the same amount of Fur proteins. In a previous report, the estimated plasmid copy number of pTT8 (the precursor plasmid of pYK596) relative to chromosomal DNA was eight $[25,26]$. This means that there are also up to eight times more Fur binding sites available for the same amount of Fur which perhaps would explain the higher leaky expression. Further modifications, such 
as an insertion of the fur gene into the expression vector, might be needed to achieve more strict expression control.

\section{Homologous expression of $\beta$-galactosidase and heterologous expression of pisGDH via $p$ Six 3}

We determined that pSix 3 was most suitable for protein expression in T. thermophilus HB27. Subsequently, we successfully expressed $\beta$-galactosidase from Thermus sp. A4 as shown in Fig. 4b. His-tagged $\beta$-galactosidase was purified using immobilized nickel-affinity chromatography, as confirmed by the appearance of a single band on SDS-PAGE (Fig. 5a), and yielded $27 \mathrm{mg} / \mathrm{L}$ of culture. This expression level was the highest achieved using this $T$. thermophilus-based system. However, this result should be considered homologous expression because the target gene was $\beta$-galactosidase from a Thermus strain.

To confirm the ability of this system to induce heterologous expression, we attempted to express glutamate dehydrogenase from the hyperthermophilic archaeon Pyrobaculum islandicum (pisGDH), which requires heat treatment to reach a fully activated form. First, the original pisGDH gene was cloned into the $\mathrm{pSix} 3$ vector. However, this plasmid did not yield protein expression in Thermus cells, which we attributed to a codon bias between Thermus and Pyrobaculum. We then codonoptimized a pisGDH gene fragment for Thermus via artificial synthesis, which enabled the successful expression of pisGDH in Thermus cells (Fig. 5b). After purification via affinity chromatography, this system yielded $9.5 \mathrm{mg}$ pis GDH/L of culture. As expected, Thermus expressed a fully active form of pisGDH without any

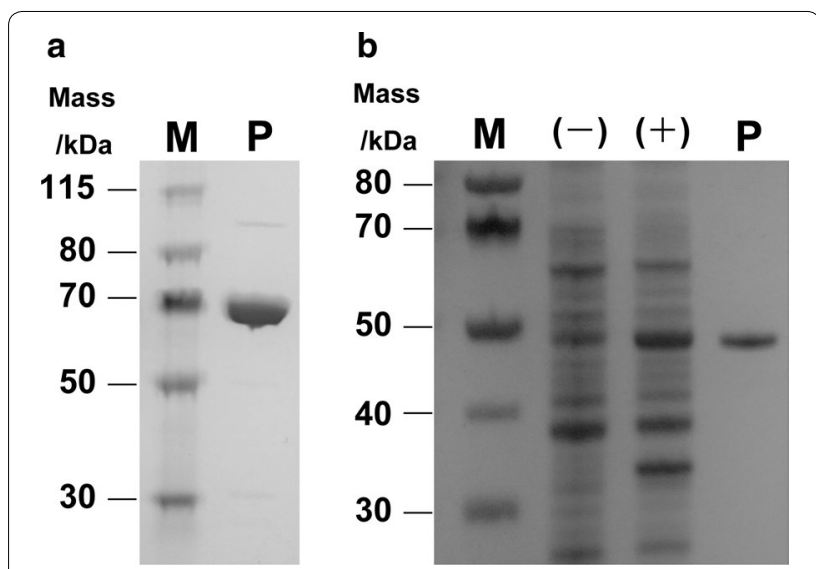

Fig. 5 Purification of thermostable $\beta$-galactosidase and pisGDH expressed in Thermus cells. a Purification of thermostable $\beta$-galactosidase. b Purification of pisGDH. (-); 0 mM silica, (+); $10 \mathrm{mM}$ silica. Lane $P$ indicates the fraction purified via nickel-affinity chromatography on a Ni-NTA column. Lane M contains the molecular mass marker further treatment, thus emphasizing the superiority of this expression system for thermostable enzyme production. A specific activity analysis yielded a value of $4.90 \mu \mathrm{mol} / \mathrm{min} / \mathrm{mg}$ for the enzymes expressed in Thermus, which was nearly identical to that of native pisGDH (3.51 $\mu \mathrm{mol} / \mathrm{min} / \mathrm{mg})$.

Our findings support our initial conjecture that fully activated thermostable enzymes could be expressed in Thermus cells cultured at high temperatures. However, we note that our original failure to express pisGDH from the original (i.e., not optimized for Thermus) sequence cannot be ignored. Thermus species have a high GC content $(\sim 70 \%)$ and therefore a very different codon usage pattern from that of other organisms. A new host strain containing tRNAs for codons that are rarely used in Thermus might be required to achieve universal translation.

\section{Conclusion}

We have reported the development of a silica-inducible promoter-based system to achieve the homologous and heterologous expression of thermostable genes in Thermus thermophilus. Notably, we successfully expressed soluble and thermostable Thermus $\beta$-galactosidase in Thermus cells and demonstrated that this system was more efficient than an E. coli-based expression system. We further optimized the promoter region via a promoter deletion assay and ultimately achieved a $\beta$-galactosidase protein yield of $27 \mathrm{mg} / \mathrm{L}$ of culture, the highest value reported for a Thermus expression system to date. Moreover, the successful use of our novel system to express the heterologous pisGDH supports our hypothesis that a Thermus-based hot expression system would enhance the production of fully active thermostable enzymes. We conclude that our novel expression system represents a substantial contribution with respect to enzymatic research and, potentially, industrial applications.

\section{Materials and methods}

\section{Strains and growth conditions}

Thermus thermophilus strains HB8 (ATCC 27634) and HB27 (ATCC BAA-163) were grown in Thermus medium (TM medium) composed of $4.0 \%(\mathrm{w} / \mathrm{v}) \mathrm{BBL}^{\mathrm{TM}}$ Polypeptone $^{\mathrm{TM}}$ Peptone (Becton-Dickinson, United States), 2.0\% $(\mathrm{w} / \mathrm{v})$ Bacto $^{\mathrm{TM}}$ Yeast Extract (Becton-Dickinson), $1.0 \%$ $(\mathrm{w} / \mathrm{v})$ sodium chloride (Nacalai tesque, Japan) and $0.1 \%$ Castenholz' basal salt solution under strong aeration in baffled flask (i.e., rotation at $180 \mathrm{rpm}$ ) at $70{ }^{\circ} \mathrm{C}[27,28]$. TM medium containing silicic acid was prepared using a $1000 \mathrm{ppm}$ sodium orthosilicate stock solution in $10 \mathrm{mM}$ $\mathrm{NaOH}$. Prior to use, the medium was $\mathrm{pH}$-adjusted to 7.2 with $\mathrm{HCl}$ and autoclaved [11]. Hygromycin $(100 \mu \mathrm{g} / \mathrm{mL})$ was added to liquid or agar medium as needed. 


\section{Plasmid constructions and overexpression of $\beta$-galactosidase}

The plasmids and primers used in this study are listed in Additional file 1: Tables S1 and S2. The Thermus cloning vector pYK596 (7733 bp), which carries a thermostable hygromycin resistance gene, was kindly provided by Dr. Koyama (National Institute of Advanced Industrial Science and Technology, Japan, unpublished). The pBGB3 plasmid containing thermostable $\beta$-galactosidase was kindly provided by Dr. Motoshima (Yotsuba Milk Products Co., Ltd, Japan) [29]. The silica-inducible expression vector pSix1 and reporter plasmid $\beta$ gal/pSix 1 were constructed as shown in Fig. 1. The putative sip promoter region (600 bp) was amplified from the chromosomal DNA of T. thermophilus HB8 (NCBI Accession Number: AP008226) using LA Taq DNA polymerase (TaKaRabio Inc., Japan) with the primers IFp6SF and IFp6SR. The MCS containing a C-terminus His-tag was amplified from pET21a (Novagen, United States) using the primers IFmcsF and IFmcsR. These amplified fragments were cloned into pYK596 at the Nhe I (2852) and Eco RI (992) sites using the In-Fusion HD cloning kit (TaKaRabio). The resultant plasmid was named pSix0 (plasmid for silica-inducible expression, $6700 \mathrm{bp}$ ). The $X$ ho I site at position 1975 nt was removed by site-directed mutagenesis with the primers pSixdexhoF and pSixdexhoR, and the resultant plasmid was named pSix1 (DDBJ Accession number: LC428096).

For the $\beta$-galactosidase reporter assay, a thermostable $\beta$-galactosidase gene of Thermus sp. A4 was PCRamplified from pBGB3 using the primers IFbgal-sixF and IFbgal-sixR. The PCR product was then cloned into linearized pSix1 amplified by inverse PCR with the primers pSix-invL and pSix-invR using the In-Fusion HD cloning kit. The resultant plasmid was named $\beta$ gal/pSix1.

To achieve the overexpression of thermostable $\beta$-galactosidase in $E$. coli, the $\beta$-galactosidase gene of Thermus sp. A4 was PCR-amplified from pBGB3 using the primers IFbgal-pETF and IFbgal-pETR. The PCR product was cloned into linearized pET21a (Novagen) after Nde I and Xho I digestion, using the In-Fusion HD cloning kit. The resultant plasmid, $\beta$ gal/pET21a, was used to transform E. coli Rosetta ${ }^{\mathrm{TM}} 2$ (DE3) competent cells (Merck Millipore, United States). A single colony of freshly transformed cells was inoculated into LB medium $(1.0 \%(\mathrm{w} / \mathrm{v})$ tryptone (Nacalai tesque), $0.5 \%(\mathrm{w} / \mathrm{v})$ yeast extract (Nacalai tesque), and $1.0 \%(\mathrm{w} / \mathrm{v})$ sodium chloride) containing $50 \mu \mathrm{g} / \mathrm{mL}$ ampicillin and $50 \mu \mathrm{g} / \mathrm{mL}$ chloramphenicol.

Expression of $\beta$-galactosidase in T. thermophilus and E. coli The recombinant $\beta$-galactosidases were expressed in both E. coli and T. thermophilus HB27. For expression in E. coli, Rosetta ${ }^{\mathrm{TM}} 2$ (DE3) competent cells (Merck Millipore) was transformed with the recombinant plasmid $\beta g a l / p E T 21 a$. Protein expression was induced by adding $0.5 \mathrm{mM}$ of isopropyl- $\beta$-D-1-thiogalactopyranoside (IPTG) to exponentially growing cells $\left(\mathrm{OD}_{660}=0.6\right)$, followed by further cell growth for $3 \mathrm{~h}$. The cells were then collected by centrifugation and lysed in an appropriate volume of BugBuster ${ }^{\circledR}$ HT Protein Extraction Reagent (Merck Millipore). The soluble and insoluble fractions were subjected to $10 \%$ SDS-PAGE. For expression in $T$. thermophilus, $5 \mathrm{~mL}$ of an overnight culture of strain HB27 harboring the plasmid $\beta$ gal/pSix1 were inoculated into $100 \mathrm{~mL}$ of freshly prepared TM medium containing $10 \mathrm{mM}$ silicic acid and cultivated at $70{ }^{\circ} \mathrm{C}$. The cells were then harvested and lysed using BugBuster ${ }^{\circledR}$ HT Protein Extraction Reagent. The soluble and insoluble fractions were subjected to $10 \%$ SDS-PAGE. Protein concentration was determined using a Quant-iT ${ }^{\mathrm{TM}}$ Protein Assay Kit (Invitrogen, United States).

The expression of His-tagged recombinant $\beta$-galactosidase was confirmed by Western blotting. Electrophoresed proteins were transblotted onto a polyvinylidene difluoride (PVDF) membrane for $30 \mathrm{~min}$ at $150 \mathrm{~mA}$ in transfer buffer containing $25 \mathrm{mM}$ Tris $(\mathrm{pH}$ 8.3), $192 \mathrm{mM}$ glycine, and $20 \%$ (v/v) methanol. The membrane was then incubated in blocking buffer $[5 \%$ skimmed milk in $1 \times$ Tris buffered saline (TBS; $5 \mathrm{mM}$ Tris, $138 \mathrm{mM} \mathrm{NaCl}$, and $2.7 \mathrm{mM} \mathrm{KCl}$ )] for $1 \mathrm{~h}$ at room temperature, and then incubated with 1/5000 diluted anti-His-tag mAb-HRP-DirecT (Medical and Biological Laboratories Co., Ltd. Japan) in blocking buffer for $30 \mathrm{~min}$. After three washes with TBS-T $(0.05 \%$ Tween 20 (Nacalai tesque, Japan) in $1 \times$ TBS), the membrane was incubated with ImmunoStar Zeta reagent (WAKO, Japan). Specific labeled proteins were visualized using an AE-9300 Ez-Capture MG imaging system (ATTO, Japan).

\section{$\beta$-Galactosidase assays}

$\beta$-Galactosidase assays were performed as previously described [30], with slight modification. Briefly, after measuring the $\mathrm{OD}_{600}, 1 \mathrm{~mL}$ aliquots of the cultures were centrifuged at $10,000 \times$ for $3 \mathrm{~min}$. Cell pellets were resuspended in $100 \mu \mathrm{L}$ of permeabilization solution $(100 \mathrm{mM}$ $\mathrm{Na}_{2} \mathrm{HPO}_{4}, 20 \mathrm{mM} \mathrm{KCl}, 2 \mathrm{mM} \mathrm{MgSO}$, $0.8 \mathrm{mg} / \mathrm{mL}$ hexadecyltrimethylammonium bromide, $0.4 \mathrm{mg} / \mathrm{mL}$ sodium deoxycholate, and $5.4 \mu \mathrm{L} / \mathrm{mL} \beta$-mercaptoethanol) and maintained for $30 \mathrm{~min}$ at $70{ }^{\circ} \mathrm{C}$. Next, $900 \mu \mathrm{L}$ of substrate mixture $\left[60 \mathrm{mM} \mathrm{Na} \mathrm{HPO}_{4}, 40 \mathrm{mM} \mathrm{NaH} \mathrm{PO}_{4}, 1 \mathrm{mg} / \mathrm{mL}\right.$ $o$-nitrophenyl- $\beta$-D-galactoside (ONPG), and $2.7 \mu \mathrm{L} / \mathrm{mL}$ $\beta$-mercaptoethanol] prewarmed to $70{ }^{\circ} \mathrm{C}$ was added to initiate the reaction. After sufficient color had developed (15-60 $\mathrm{min})$, the reactions were terminated by the addition of $1 \mathrm{~mL}$ of $1 \mathrm{M} \mathrm{Na}_{2} \mathrm{CO}_{3}$. The reaction mixtures were 
then centrifuged at $10,000 \times g$ for $5 \mathrm{~min}$, and the $\mathrm{A}_{420}$ values of the supernatants were recorded. Enzyme activities were expressed in Miller units (MU) and were calculated as the $\mathrm{A}_{420} /$ reaction time (min)/culture volume assayed $(\mathrm{mL}) / \mathrm{OD}_{600}$. In all experiments, activity was measured in three independent assays.

\section{Promoter deletion analysis}

To identify the minimal region of the sip promoter, a series of promoter deletion fragments were fused to the thermostable $\beta$-galactosidase gene from Thermus sp. A4. Specifically, the promoter region was truncated by inverse PCR of $\beta \mathrm{gal} / \mathrm{pSix} 1$ with the primers listed in Additional file 1: Table S2. T. thermophilus HB27 was transformed with these plasmids and then cultivated in TM medium containing $10 \mathrm{mM}$ silicic acid at $70{ }^{\circ} \mathrm{C}$ for $24 \mathrm{~h}$. The $\beta$-galactosidase activity levels were determined as described above. Consequently, the 100-bp sip promoter region was identified as most effective. Accordingly, an expression vector containing this 100-bp sip promoter region and MCS was created in the same way. The resultant plasmid was named pSix 3 and has been deposited in the DDBJ database (Accession number: LC504201).

\section{Statistical analysis}

The level of expression of $\beta$-galactosidase in induced cells was compared to the level of expression in uninduced cells. The data were presented as the mean \pm SE. Three independent samples were analyzed using Student's $t$ test using Microsoft Excel $^{\circledR}$. Statistical differences were considered significant if the $\mathrm{p}$ value was less than 0.05 (denoted by stars *p $<0.05$; ** $\mathrm{p}<0.005$ ).

\section{Expression of $\beta$-galactosidase from $\mathrm{pSix} 3$}

A thermostable $\beta$-galactosidase gene was cloned into pSix3 as described earlier in this section. His-tagged $\beta$-galactosidase was expressed in TM medium containing $10 \mathrm{mM}$ silicic acid for $48 \mathrm{~h}$. Subsequently, the cells were collected by centrifugation, resuspended in IMAC30 Buffer [20 mM Tris- $\mathrm{HCl}$ (pH 8.0), $300 \mathrm{mM} \mathrm{NaCl}, 30 \mathrm{mM}$ imidazole], and disrupted using an ultrasonic disrupter. The cell debris was removed by centrifugation, and the supernatant was applied to a nickel-nitrilotriacetic acid (Ni-NTA) agarose column (Qiagen, Germany) and eluted with IMAC250 Buffer [20 mM Tris- $\mathrm{HCl}(\mathrm{pH} 8.0)$, $300 \mathrm{mM} \mathrm{NaCl}, 250 \mathrm{mM}$ imidazole]. The purified fraction was desalted and concentrated by ultrafiltration (Merck Millipore). The final protein concentration was determined using a Quant-i $\mathrm{T}^{\mathrm{TM}}$ Protein Assay Kit (Invitrogen).

\section{Heterologous expression of PisGDH in Thermus spp.}

The Pyrobaculum islandicum glutamate dehydrogenase gene sequence was optimized for expression in T. thermophilus HB27 by substituting rare codons found in the latter organism (Codon Usage Database: https://www. kazusa.or.jp/codon/). The original and optimized pisGDH sequences are listed in Additional file 1: Table S4. The optimized pisGDH sequence was synthesized artificially as a gBlocks $^{\circledR}$ Gene Fragment (Integrated DNA Technologies, United States). This fragment was amplified by PCR and cloned into pSix3 using the In-Fusion HD cloning kit. Fifty milliliters of a pre-culture of this transformant were inoculated into $1 \mathrm{~L}$ of freshly prepared TM medium containing $10 \mathrm{mM}$ silica and cultivated for $48 \mathrm{~h}$.

His-tagged pisGDH was purified as follows. First, the cells were harvested and resuspended in an appropriate volume of Binding/Wash Buffer $[10 \mathrm{mM}$ potassium phosphate buffer ( $\mathrm{pH} 7.2$ ), $300 \mathrm{mM} \mathrm{NaCl}, 20 \mathrm{mM}$ imidazole, $10 \%$ glycerol] and disrupted by ultrasonication. After removing the cell debris by centrifugation, the supernatant was applied to a Ni-NTA agarose column (Qiagen). The target protein was eluted with $300 \mathrm{mM}$ imidazole, and the eluates were dialyzed against Standard Buffer [10 mM potassium phosphate buffer ( $\mathrm{pH} 7.2)$, $1 \mathrm{mM}$ EDTA, $0.1 \mathrm{mM}$ DTT, 10\% glycerol]. Samples for the activity assay were further purified by size exclusion chromatography. The protein concentrations were determined using a Bio-Rad Protein Assay (Bio-Rad). The enzymatic activity of pisGDH was assayed spectrophotometrically by monitoring the increase of NADH at $340 \mathrm{~nm}[31]$.

\section{Supplementary information}

Supplementary information accompanies this paper at https://doi. org/10.1186/s12934-020-01385-2.

Additional file 1: Table S1. Plasmids used in this study. Table S2. Primers used in this study. Figure S1. Effect of silicic acid on the growth of Thermus thermophilus HB27 cells harboring the $\beta g a l / p S i x 1$ plasmid. Table S3. $\beta$-Galactosidase activity after medium exchange. Figure S2. Comparison of putative sip promoter region between T. thermophilus HB8 and HB27 Figure S3. Homologous recombination between chromosomal DNA and plasmid DNA. Table S4. Sequence of pis GDH for expression in Thermus thermophilus.

\section{Abbreviations}

pisGDH: Glutamate dehydrogenase from Pyrobaculum islandicum; $A B C$ transporter: ATP-binding cassette transporter; Sip: Silica-induced protein; MCS: Multi-cloning site; OD: Optical density; qRT-PCR: Quantitative reverse transcription polymerase chain reaction; MU: Miller unit; DP: 2,2'-dipyridyl, phen; 1,10-phenanthroline; IPTG: Isopropyl- $\beta$-D-1-thiogalactopyranoside; SDS-PAGE: Sodium dodecyl sulfate-polyacrylamide gel electrophoresis; CDS: Coding sequence; PVDF: Polyvinylidene difluoride; ONPG: o-nitrophenyl- $\beta$-Dgalactoside; IMAC: Immobilized metal affinity chromatography; NADH: Nicotinamide Adenine Dinucleotide - Hydrogen; EDTA: Ethylenediaminetetraacetic acid; DTT: Dithiothreitol. 


\section{Acknowledgements}

We thank Dr. Yoshinori Koyama for providing the pYK596 plasmid and Dr Motoshima, who kindly provided us with the pBGB3 plasmid and Thermus sp. A4 strain. The authors would also like to thank Enago (http://www.enago.jp) for performing the English language review.

\section{Authors' contributions}

YF, SG, and YS performed the experiments. SG particularly assisted with the enzymatic analysis. YF and KD supervised the project. YF drafted the manuscript. All authors read and approved the final manuscript.

\section{Funding}

This study was funded by JSPS KAKENHI (Grant number 23780085 and 17K15246) and by the Takahashi Industrial and Economic Research Foundation.

\section{Availability of data and materials}

The recombinant strains described in this work will be made available upon request to the corresponding author. Data sharing is not applicable to this article, as no datasets were generated or analyzed during this study.

\section{Ethics approval and consent to participate}

This article does not describe any studies involving human participants or animals that were performed by any of the authors.

\section{Competing interests}

The authors declare that they have no competing interests.

\section{Author details}

${ }^{1}$ Institute of Genetic Resources, Faculty of Agriculture, Kyushu University, 744 Motooka, Nishi-ku, Fukuoka 819-0395, Japan. ${ }^{2}$ Graduate School of Science and Engineering, Soka University, 1-236, Tangi-cho, Hachioji-shi, Tokyo 192-8577, Japan.

Received: 19 March 2020 Accepted: 1 June 2020

Published online: 08 June 2020

\section{References}

1. Cava F, Hidalgo A, Berenguer J. Thermus thermophilus as biological model. Extremophiles. 2009;13:213-31.

2. Taylor MP, van Zyl L, Tuffin IM, Leak DJ, Cowan DA. Genetic tool development underpins recent advances in thermophilic whole-cell biocatalysts. Microb Biotechnol. 2011;4:438-48.

3. Niehaus F, Bertoldo C, Kahler M, Antranikian G. Extremophiles as a source of novel enzymes for industrial application. Appl Microbiol Biotechnol. 1999;51:711-29.

4. Adams MW, Kelly RM. Finding and using hyperthermophilic enzymes. Trends Biotechnol. 1998;16:329-32.

5. Hidalgo A, Betancor L, Moreno R, Zafra O, Cava F, Fernandez-Lafuente R, Guisan JM, Berenguer J. Thermus thermophilus as a cell factory for the production of a thermophilic Mn-dependent catalase which fails to be synthesized in an active form in Escherichia coli. Appl Environ Microbiol. 2004;70:3839-44.

6. Koyama Y, Okamoto S, Furukawa K. Cloning of alpha- and beta-galactosidase genes from an extreme thermophile, Thermus strain T2, and their expression in Thermus thermophilus HB27. Appl Environ Microbiol. 1990:56:2251-4.

7. Moreno R, Haro A, Castellanos A, Berenguer J. High-level overproduction of His-tagged Tth DNA polymerase in Thermus thermophilus. Appl Environ Microbiol. 2005;71:591-3.

8. Park HS, Kilbane JJ 2nd. Gene expression studies of Thermus thermophilus promoters PdnaK, Parg and Pscs-mdh. Lett Appl Microbiol. 2004;38:415-22.

9. Park HS, Kayser KJ, Kwak JH, Kilbane JJ 2nd. Heterologous gene expression in Thermus thermophilus: beta-galactosidase, dibenzothiophene monooxygenase, PNB carboxy esterase, 2-aminobiphenyl-2,3-diol dioxygenase, and chloramphenicol acetyl transferase. J Ind Microbiol Biotechnol. 2004;31:189-97.

10. Aulitto M, Fusco S, Fiorentino G, Limauro D, Pedone E, Bartolucci $\mathrm{S}$, Contursi P. Thermus thermophilus as source of thermozymes for biotechnological applications: homologous expression and biochemical characterization of an alpha-galactosidase. Microb Cell Fact. 2017;16:28.

11. Doi K, Fujino Y, Inagaki F, Kawatsu R, Tahara M, Ohshima T, Okaue Y, Yokoyama T, Iwai S, Ogata S. Stimulation of expression of a silicainduced protein (Sip) in Thermus thermophilus by supersaturated silicic acid. Appl Environ Microbiol. 2009;75:2406-13.

12. Fujino $Y$, Nagayoshi $Y$, I wase M, Yokoyama T, Ohshima T, Doi K. Silica-induced protein (Sip) in thermophilic bacterium Thermus thermophilus responds to low iron availability. Appl Environ Microbiol. 2016;82:3198-207.

13. Goda S, Kojima M, Nishikawa Y, Kujo C, Kawakami R, Kuramitsu S, Sakuraba H, Hiragi Y, Ohshima T. Intersubunit interaction induced by subunit rearrangement is essential for the catalytic activity of the hyperthermophilic glutamate dehydrogenase from Pyrobaculum islandicum. Biochemistry. 2005:44:15304-13.

14. Miller JH. Experiments in molecular genetics. Cold Spring Harbor: Cold Spring Harbor Laboratory Press; 1972.

15. Moreno R, Zafra O, Cava F, Berenguer J. Development of a gene expression vector for Thermus thermophilus based on the promoter of the respiratory nitrate reductase. Plasmid. 2003;49:7.

16. Fujita A, Sato T, Koyama Y, Misumi Y. A reporter gene system for the precise measurement of promoter activity in Thermus thermophilus HB27. Extremophiles. 2015;19:1193-201.

17. Wandersman C, Delepelaire P. Bacterial iron sources: from siderophores to hemophores. Annu Rev Microbiol. 2004;58:611-47.

18. Abdul-Tehrani H, Hudson AJ, Chang YS, Timms AR, Hawkins C, Williams JM, Harrison PM, Guest JR, Andrews SC. Ferritin mutants of Escherichia coli are iron deficient and growth impaired, and fur mutants are iron deficient. J Bacteriol. 1999;181:1415-28.

19. Baneyx F, Mujacic M. Recombinant protein folding and misfolding in Escherichia coli. Nat Biotechnol. 2004;22:1399-408.

20. Diruggiero J, Robb FT. Expression and in vitro assembly of recombinant glutamate dehydrogenase from the hyperthermophilic archaeon Pyrococcus furiosus. Appl Environ Microbiol. 1995;61:159-64.

21. Schultes $V$, Jaenicke R. Folding intermediates of hyperthermophilic D-glyceraldehyde-3-phosphate dehydrogenase from Thermotoga maritima are trapped at low temperature. FEBS Lett. 1991:290:235-8.

22. Siddiqui MA, Fujiwara S, Takagi M, Imanaka T. In vitro heat effect on heterooligomeric subunit assembly of thermostable indolepyruvate ferredoxin oxidoreductase. FEBS Lett. 1998;434:372-6.

23. Ramirez-Arcos S, Fernandez-Herrero LA, Berenguer J. A thermophilic nitrate reductase is responsible for the strain specific anaerobic growth of Thermus thermophilus HB8. Biochim Biophys Acta. 1998;1396:215-27.

24. Vazquez-Tello A, Castan P, Moreno R, Smith JM, Berenguer J, Cedergren R. Efficient trans-cleavage by the Schistosoma mansoni SMalpha1 hammerhead ribozyme in the extreme thermophile Thermus thermophilus. Nucleic Acids Res. 2002;30:1606-12.

25. Takayama G, Kosuge T, Maseda H, Nakamura A, Hoshino T. Nucleotide sequence of the cryptic plasmid pTT8 from Thermus thermophilus HB8 and isolation and characterization of its high-copy-number mutant. Plasmid. 2004;51:227-37.

26. Ohtani N, Tomita M, Itaya M. The third plasmid pVV8 from Thermus thermophilus HB8: isolation, characterization, and sequence determination. Extremophiles. 2012;16:237-44.

27. Koyama Y, Hoshino T, Tomizuka N, Furukawa K. Genetic transformation of the extreme thermophile Thermus thermophilus and of other Thermus spp. J Bacteriol. 1986;166:338-40.

28. Ramaley RF, Hixson J. Isolation of a nonpigmented, thermophilic bacterium similar to Thermophilic bacterium similar to Thermus aquaticus. J Bacteriol. 1970;103:527-8.

29. Ohtsu N, Motoshima H, Goto K, Tsukasaki F, Matsuzawa H. Thermostable beta-galactosidase from an extreme thermophile, Thermus sp. 
A4: enzyme purification and characterization, and gene cloning and sequencing. Biosci Biotechnol Biochem. 1998;62:1539-45.

30. Zhang X, Bremer H. Control of the Escherichia coli rrnB P1 promoter strength by ppGpp. J Biol Chem. 1995;270:11181-9.

31. Kujo C, Ohshima T. Enzymological characteristics of the hyperthermostable NAD-dependent glutamate dehydrogenase from the archaeon Pyrobaculum islandicum and effects of denaturants and organic solvents. Appl Environ Microbiol. 1998;64:2152-7.

\section{Publisher's Note}

Springer Nature remains neutral with regard to jurisdictional claims in published maps and institutional affiliations.
Ready to submit your research? Choose BMC and benefit from:

- fast, convenient online submission

- thorough peer review by experienced researchers in your field

- rapid publication on acceptance

- support for research data, including large and complex data types

- gold Open Access which fosters wider collaboration and increased citations

- maximum visibility for your research: over 100M website views per year

At BMC, research is always in progress.

Learn more biomedcentral.com/submissions 